\title{
In-Plane Vibration Analysis of Asymmetric Curved Beams Using DQM
}

\author{
Ki-Jun Kang ${ }^{1^{*}}$ and Young-Woo Kim ${ }^{1}$ \\ ${ }^{1}$ Department of Automotive Engineering, Hoseo University \\ $\mathrm{DQM}$ 을 이용한 비대칭 곡선보의 내평면 진동해석 \\ 강기준 ${ }^{18}$, 김영우 \\ ${ }^{1}$ 호서대학교 공과대학 자동차공학과
}

\begin{abstract}
The free in-plane vibration of asymmetric circular curved beams with varying cross-section is analyzed by the differential quadrature method (DQM) neglecting transverse shearing deformation. Natural frequencies are calculated for the beams with various opening angles and boundary conditions. Results obtained by the DQM are compared with available results by other methods in the literature. It is found that the DQM gives the good accuracy even with a small number of grid points.

요 약 미분구적법을 이용하여, 전단변형을 고려하지 않은, 단면적이 변하는 비대칭 곡선 보의 면내 자유진동을 해 석하였다. 다양한 경계조건 및 굽힘 각에 따른 진동수를 계산하였고, 그 결과를 다른 수치해석들과 비교하였다. 미분 구적법은 비교적 적은 요소를 사용하고도 정확한 해석결과를 보여준다.
\end{abstract}

Key Words : Asymmetric Curved Beam, DQM, Fundamental Frequency, Numerical Method

\section{Introduction}

The early investigators into the in-plane vibration of rings were Hoppe [1] and Love [2]. Love [2] improved on Hoppe's theory by allowing for stretching of the ring. Archer [3] carried out for a mathematical study of the in-plane inextensional vibrations of an incomplete circular ring of small cross section with the basic equations of motion. Auciello and De Rosa [4] reviewed the free vibrations of circular arches and briefly illustrated a number of other approaches.

A rather efficient alternate procedure for the solution of partial differential equations is the method of differential quadrature which was introduced by Bellman and Casti [5]. This simple direct technique can be applied to a large number of cases to circumvent the difficulties of programming complex algorithms for the computer, as well as excessive use of storage. This method is used in the present work to analyze the free in-plane inextensional vibrations for asymmetric curved beams with varying cross-section. Results are compared with numerical solutions by the Rayleigh-Ritz, the cells discretization method (C.D.M.), or the SAP 90 finite element solution, which is one of the engineering simulation softwares[6].

\section{Governing Differential Equations}

The curved beam considered is shown in Figure 1. A point on the centroidal axis is defined by the angle $\theta$, measured from the left support. The tangential and radial

This research was supported by the Academic Research Fund of Hosses University in 2009 (2009-0138).

*Corresponding Author : Kijun Kang(kjkang@hoseo.edu)

Received June 9, 2010

Revised (1st June 30, 2010, 2nd August 2, 2010)

Accepted August 10, 2010 
displacements of the arch axis are $w$ and $u$, respectively. Here, $r$ is the radius of the centroidal axis. These displacements are considered to be positive in the directions indicated.

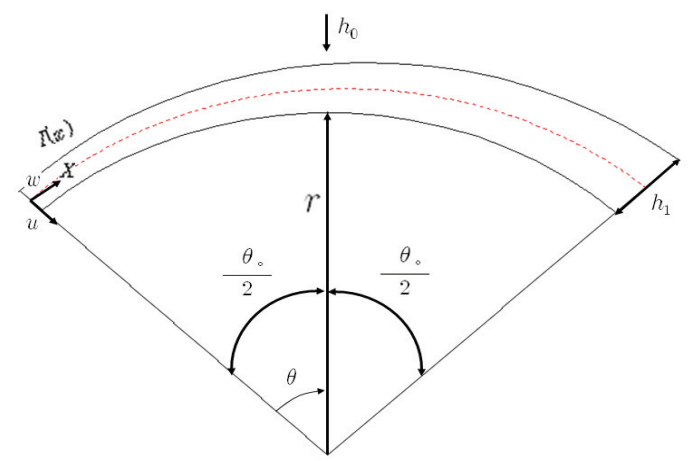

[Fig. 1] Coordinate system for curved beam

The basic equations of motion given by Love [2] is a single sixth order differential equation using $w(\theta, t)=W(\theta) T(t)$.

$$
\begin{aligned}
& \frac{W^{(I V)}}{\theta_{0}^{6}}(f(X))+\frac{W^{(V)}}{\theta_{0}^{5}}\left(3 \frac{f^{\prime}(X)}{\theta_{0}}\right)+ \\
& \frac{W^{(V I)}}{\theta_{0}^{4}}\left(3 \frac{f^{\prime \prime}(X)}{\theta_{0}^{2}}+2 f(X)\right)+\frac{W^{\prime \prime \prime}}{\theta_{0}^{3}}\left(\frac{f^{\prime \prime \prime}(X)}{\theta_{0}^{3}}+4 \frac{f^{\prime}(X)}{\theta_{0}}\right) \\
& +\frac{W^{\prime \prime}}{\theta_{0}^{2}}\left(3 \frac{f^{\prime \prime}(X)}{\theta_{0}^{2}}+f(X)\right)+\frac{W^{\prime}}{\theta_{0}}\left(\frac{f^{\prime \prime \prime}(X)}{\theta_{0}^{3}}+\frac{f^{\prime}(X)}{\theta_{0}}\right) \\
& =\frac{m r^{4}}{E I_{0}} \omega^{2}\left(-W+\frac{W^{\prime \prime}}{\theta_{0}^{2}}\right)
\end{aligned}
$$

where $I(x)$ is $I_{0} f(X)$, and each prime denotes one differentiation with respect to the dimensionless distance coordinate $X$, defined as equations (2) and (3), respectively.

Here $f(X)$ and $I_{0}$ are the function of the cross-section variation law and the area moment of inertia of the varying cross section associated with the height of the cross-section $h_{0}$ at the crown, respectively. In the following the simple case in which the cross-section varies linearly is examined, because it seems the only law which has been studied by Auciello and De Rosa [4].
Consider then the beam structure with a rectangular cross-section shown in Figure 1. in which the height of the cross-section varies linearly from $h_{1}$ at the supports to $h_{0}$ at the crown, according to the law

$$
\begin{aligned}
& I(x)=I_{0} f(X), \\
& f(X)=[1+(2 \eta(X-0.5))]^{3}
\end{aligned}
$$

where $h_{1}$ is $(1+\eta) h_{0}$, and $\eta$ is the ratio of the heights. The dimensionless distance coordinate defines as

$$
X=\frac{\theta}{\theta_{0}}
$$

If the curved beam is clamped at $\theta=0$ and $\theta=\theta_{0}$, then the boundary conditions take the form

$$
\begin{aligned}
w(0) & =w^{\prime}(0)=w^{\prime \prime}(0) \\
& =w\left(\theta_{0}\right)=w^{\prime}\left(\theta_{0}\right)=w^{\prime \prime}\left(\theta_{0}\right)=0
\end{aligned}
$$

If the curved beam is simply supported at $\theta=0$ and $\theta=\theta_{0}$, then the boundary

$$
\begin{aligned}
w(0) & =w^{\prime}(0)=w^{\prime \prime \prime}(0) \\
& =w\left(\theta_{0}\right)=w^{\prime}\left(\theta_{0}\right)=w^{\prime \prime \prime}\left(\theta_{0}\right)=0(5)
\end{aligned}
$$

\section{Differential Quadrature Method(DQM)}

It was applied for the first time to static analysis of structural components by Jang et al. [7]. Recently, Kang and Han [8] applied the method to the static analysis of circular curved beams using classical and shear deformable beam theories, and Kang and Kim [9] have analyzed the in-plane vibration of curved beams considering shear deformation using DQM From a mathematical point of view, the application of the differential quadrature method to a partial differential equation can be expressed as follows:

$$
\begin{aligned}
L\{f(x)\}_{i} & =\sum_{j=1}^{N} W_{i j} f\left(x_{j}\right) \text { for } \\
i, \quad j & =1,2, \ldots, N
\end{aligned}
$$


where $L$ denotes a differential operator, $x_{j}$ are the discrete points considered in the domain, $f\left(x_{j}\right)$ are the function values at these points, $W_{i j}$ are the weighting coefficients attached to these function values, and $N$ denotes the number of discrete points in the domain. This equation, thus, can be expressed as the derivatives of a function at a discrete point in terms of the function values at all discrete points in the variable domain.

Figure 2 represents $N$ sets of $N$ linear algebraic equations, giving a unique solution for the weighting coefficients, $W_{i j}$, since the coefficient matrix is a Vandermonde matrix which always has an inverse as described by Hamming [10].

Set governing equation of systems - Eqs. 1 4

Find $W_{i j}$ in Eq. 6 for Eqs. 1, 4, and 5

\begin{tabular}{|lll|}
\hline Replacing governing & equations (Eq. 1) by \\
weighting coefficient & $W_{i j}$ (Eq. 6) & \\
\hline
\end{tabular}

Get DQM equations (Eq. 7): $\mathrm{N}$ sets of $\mathrm{N}$ algebraic equations for the unknown function values at prescribed space points (13 points used )

Apply boundary conditions (Eqs. 8 13) to DQM
equations (Eq. 7) and obtain eigenvalue equations

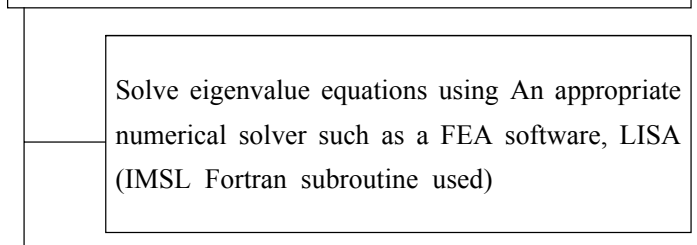

Get appropriate frequency parameters

for systems (results showed in Tables 1 6)

[Fig. 2] Flow chart for solving system model

\section{Application}

Applying the DQM to equation (1) gives

$$
\begin{aligned}
& \frac{1}{\theta_{0}^{6}} \sum_{j=1}^{N} F_{i j} W_{j}\left(f\left(X_{i}\right)\right) \\
& +\frac{1}{\theta_{0}^{5}} \sum_{j=1}^{N} E_{i j} W_{j}\left(\frac{3}{\theta_{0}} \sum_{j=1}^{N} A_{i j} f\left(X_{j}\right)\right) \\
& +\frac{1}{\theta_{0}^{4}} \sum_{j=1}^{N} D_{i j} W_{j}\left(\frac{3}{\theta_{0}^{2}} \sum_{j=1}^{N} B_{i j} f\left(X_{j}\right)+2 f\left(X_{i}\right)\right. \\
& +\frac{1}{\theta_{0}^{3}} \sum_{j=1}^{N} C_{i j} W_{j}\left(\frac{1}{\theta_{0}^{3}} \sum_{j=1}^{N} C_{i j} f\left(X_{j}\right)+\frac{4}{\theta_{0}} \sum_{j=1}^{N} A_{i j} f\left(X_{j}\right)\right) \\
& +\frac{1}{\theta_{0}^{2}} \sum_{j=1}^{N} B_{i j} W_{j}\left(\frac{3}{\theta_{0}^{2}} \sum_{j=1}^{N} B_{i j} f\left(X_{j}\right)+f\left(X_{i}\right)\right) \\
& +\frac{1}{\theta_{0}} \sum_{j=1}^{N} A_{i j} W_{j}\left(\frac{1}{\theta_{0}^{3}} \sum_{j=1}^{N} C_{i j} f\left(X_{j}\right)+\frac{1}{\theta_{0}} \sum_{j=1}^{N} A_{i j} f\left(X_{i}\right)\right) \\
& =\lambda^{2}\left(-W_{i}+\frac{1}{\theta_{0}^{2}} \sum_{j=1}^{N} B_{i j} W_{j}\right)
\end{aligned}
$$

where $A_{i j}, B_{i j}, C_{i j}, D_{i j}, E_{i j}$, and $F_{i j}$ are the weighting coefficients for the first-, the second-, the third-, the fourth-, the fifth-, and the sixth-order derivatives, respectively, along the dimensionless axis. and $\lambda^{2}$ is the non-dimensional frequency, $\frac{m r^{4} \omega^{2}}{E I_{0}}$.

The boundary conditions for clamped ends, given by equation (4), can be expressed in differential quadrature form as follows:

$$
\begin{array}{lll}
W_{1}=0 & \text { at } & X=0 \\
W_{N}=0 & \text { at } & X=1 \\
\sum_{j=1}^{N} A_{2 j} W_{j}=0 & \text { at } & X=0+\delta \\
\sum_{j=1}^{N} A_{(N-1) j} W_{j}=0 & \text { at } & X=1-\delta \\
\sum_{j=1}^{N} B_{3 j} W_{j}=0 & \text { at } & X=0+2 \delta \\
\sum_{j=1}^{N} B_{(N-2) j} W_{j}=0 & \text { at } & X=1-2 \delta
\end{array}
$$

Here, $\delta$ denotes a very small distance measured along the dimensionless axis from the boundary ends. Similarly, simply supported and clamped-simply supported ends can be easily accommodated by combining these equations; simply change the weighting coefficients. 


\section{Numerical Results and Comparisons}

Based on the above derivations, Fundamental frequency parameters, $\lambda=\left(\omega^{2} m r^{4} / E I_{0}\right)^{1 / 2}$, for asymmetric circular curved beams are evaluated for the rectangular cross sections under the various boundary conditions, and the numerical results by the DQM are compared with other numerical solutions by Auciello and De Rosa [4]. In the following the simple case in which the cross-section varies linearly is examined, because it seems the only law which has been studied in the literature.

Tables 1 and 2 present the results of convergence

[Table 1] Fundamental frequency parameters, $\lambda=\sqrt{\omega^{2}\left(m r^{4} / E I_{0}\right)}$, for in-plane vibration of non-uniform curved beams with simply-simply supported ends including a range of $N ; \eta=0.1$ and $\delta=1 \times 10^{-6} ; f(X)=[1+(2 \eta(X-0.5))]^{3}$

\begin{tabular}{|c|c|c|c|c|c|c|c|}
\hline \multirow{2}{*}{$\begin{array}{c}\theta_{0} \\
\text { (degrees) }\end{array}$} & \multirow{2}{*}{ Rayleigh-Ritz } & \multirow{2}{*}{ C. D. M. } & \multicolumn{5}{|c|}{$N$ (DQM) } \\
\cline { 4 - 8 } & & & 9 & 11 & 13 & 15 & 17 \\
\hline 60 & 33.430 & 33.484 & 32.841 & 33.580 & 33.543 & 33.793 & 33.820 \\
\hline
\end{tabular}

[Table 2] Fundamental frequency parameters, $\lambda=\sqrt{\omega^{2}\left(m r^{4} / E I_{0}\right)}$, for in-plane vibration of non-uniform curved beams with simply-simply supported ends including a range of $\delta ; \eta=0.1$ and $N=13 ; f(X)=[1+(2 \eta(X-0.5))]^{3}$

\begin{tabular}{|c|c|c|c|c|c|c|c|}
\hline$\theta_{0}$ & \multirow{2}{*}{$\begin{array}{c}\text { Rayleigh-Ritz } \\
\text { (degrees) }\end{array}$} & C. D. M. & \multicolumn{5}{|c|}{$\delta$ (DQM) } \\
\cline { 4 - 7 } & & & $1 \times 10^{-4}$ & $1 \times 10^{-5}$ & $1 \times 10^{-6}$ & $1 \times 10^{-7}$ & $1 \times 10^{-8}$ \\
\hline 60 & 33.430 & 33.484 & 33.559 & 33.545 & 33.543 & 33.554 & 33.565 \\
\hline
\end{tabular}

[Table 3] Fundamental frequency parameters, $\lambda=\sqrt{\omega^{2}\left(m r^{4} / E I_{0}\right)}$, for in-plane vibration of non-uniform curved beams with simply-simply supported ends; $f(X)=[1+(2 \eta(X-0.5))]^{3}$

\begin{tabular}{|c|c|c|c|c|c|}
\hline$\eta$ & $\theta_{0}$ & Rayleigh-Ritz & C. D. M. & F. E. M. & DQM \\
\hline \multirow{6}{*}{0.1} & 10 & 1286.5 & 1287.8 & - & 1290.4 \\
\hline & 20 & 319.09 & 320.11 & 320.81 & 320.75 \\
\hline & 30 & 141.05 & 140.92 & - & 141.19 \\
\hline & 40 & 78.069 & 78.220 & 74.438 & 78,371 \\
\hline & 50 & 49.124 & 49.218 & - & 49.306 \\
\hline & 60 & 33.430 & 33.484 & 33.621 & 33.543 \\
\hline \multirow{6}{*}{0.2} & 10 & 1279.6 & 1278.7 & - & 1281.3 \\
\hline & 20 & 318.27 & 317.84 & 318.43 & 318.50 \\
\hline & 30 & 139.92 & 139.91 & - & 140.18 \\
\hline & 40 & 77.638 & 77.660 & 77.884 & 77.808 \\
\hline & 50 & 48.848 & 48.864 & - & 48.947 \\
\hline & 60 & 33.229 & 33.242 & 33.366 & 33.294 \\
\hline \multirow{6}{*}{0.3} & 10 & 1266.2 & 1263.2 & - & 1265.8 \\
\hline & 20 & 313.10 & 313.97 & 314.41 & 314.62 \\
\hline & 30 & 138.39 & 138.21 & - & 138.47 \\
\hline & 40 & 76.551 & 76.708 & 76.900 & 76.845 \\
\hline & 50 & 48.139 & 48.282 & - & 48.337 \\
\hline & 60 & 32.828 & 32.830 & 32.947 & 32.875 \\
\hline \multirow{6}{*}{0.4} & 10 & 1238.6 & 1240.7 & - & 1243.39 \\
\hline & 20 & 307.93 & 308.37 & 308.58 & 308.99 \\
\hline & 30 & 135.69 & 135.73 & - & 135.99 \\
\hline & 40 & 75.217 & 75.330 & 75.484 & 75.449 \\
\hline & 50 & 47.272 & 47.390 & - & 47.450 \\
\hline & 60 & 32.208 & 32.233 & 32.336 & 32.260 \\
\hline
\end{tabular}


[Table 4] Fundamental frequency parameters, $\lambda=\sqrt{\omega^{2}\left(m r^{4} / E I_{0}\right)}$, for in-plane vibration of non-uniform curved beams with clamped-clamped ends; $f(X)=[1+(2 \eta(X-0.5))]^{3}$

\begin{tabular}{|c|c|c|c|c|c|}
\hline$\eta$ & $\theta_{0}$ & Rayleigh-Ritz & C. D. M. & F. E. M. & DQM \\
\hline 0.1 & $\begin{array}{l}10 \\
20 \\
30 \\
40 \\
50 \\
60\end{array}$ & $\begin{array}{l}1999.9 \\
498.33 \\
220.06 \\
122.70 \\
77.632 \\
53.172\end{array}$ & $\begin{array}{l}2000.5 \\
499.44 \\
220.56 \\
122.97 \\
77.813 \\
53.303\end{array}$ & $\begin{array}{c}- \\
502.02 \\
- \\
123.65 \\
- \\
53.674\end{array}$ & $\begin{array}{l}2016.7 \\
502.25 \\
221.79 \\
123.65 \\
78.245 \\
53.598\end{array}$ \\
\hline 0.2 & $\begin{array}{l}10 \\
20 \\
30 \\
40 \\
50 \\
60 \\
\end{array}$ & $\begin{array}{l}1999.9 \\
497.84 \\
219.80 \\
122.55 \\
77.540 \\
53.108 \\
\end{array}$ & $\begin{array}{l}1990.1 \\
495.60 \\
218.86 \\
122.02 \\
77.214 \\
52.893 \\
\end{array}$ & $\begin{array}{c}- \\
498.90 \\
- \\
122.88 \\
- \\
53.291 \\
\end{array}$ & $\begin{array}{l}2001.8 \\
498.52 \\
220.14 \\
122.72 \\
77.654 \\
53.190 \\
\end{array}$ \\
\hline 0.3 & $\begin{array}{l}10 \\
20 \\
30 \\
40 \\
50 \\
60\end{array}$ & $\begin{array}{l}1978.2 \\
492.42 \\
217.36 \\
121.16 \\
76.647 \\
52,598\end{array}$ & $\begin{array}{l}1963.7 \\
489.05 \\
215.97 \\
120.41 \\
76.195 \\
52.196\end{array}$ & $\begin{array}{c}- \\
492.75 \\
- \\
121.38 \\
- \\
52.643\end{array}$ & $\begin{array}{l}1976.2 \\
492.12 \\
217.30 \\
121.13 \\
76.641 \\
52.491\end{array}$ \\
\hline 0.4 & $\begin{array}{l}10 \\
20 \\
30 \\
40 \\
50 \\
60\end{array}$ & $\begin{array}{l}1934.2 \\
481.34 \\
212.69 \\
118.63 \\
75.019 \\
51,385\end{array}$ & $\begin{array}{l}1925.6 \\
479.55 \\
211.78 \\
118.07 \\
74.717 \\
51.184\end{array}$ & $\begin{array}{c}- \\
483.97 \\
- \\
119.25 \\
- \\
51.722\end{array}$ & $\begin{array}{l}1938.8 \\
482.79 \\
213.17 \\
118.81 \\
75.165 \\
51.471\end{array}$ \\
\hline
\end{tabular}

[Table 5] Fundamental frequency parameters, $\lambda=\sqrt{\omega^{2}\left(m r^{4} / E I_{0}\right)}$, for in-plane vibration of non-uniform curved beams with simply supported-clamped ends; $f(X)=[1+(2 \eta(X-0.5))]^{3}$

\begin{tabular}{|c|c|c|c|c|c|}
\hline$\eta$ & $\theta_{0}$ & Rayleigh-Ritz & C. D. M. & F. E. M. & DQM \\
\hline 0.1 & $\begin{array}{l}10 \\
20 \\
30 \\
40 \\
50 \\
60\end{array}$ & $\begin{array}{l}1637.5 \\
407.31 \\
179.86 \\
100.17 \\
63.240 \\
43.151\end{array}$ & $\begin{array}{l}1636.7 \\
407.32 \\
179.67 \\
100.01 \\
63.152 \\
43.151\end{array}$ & $\begin{array}{c}- \\
407.97 \\
- \\
100.31 \\
- \\
43.315\end{array}$ & $\begin{array}{l}1642.8 \\
408.81 \\
180.31 \\
100.35 \\
63.364 \\
43.291\end{array}$ \\
\hline 0.2 & $\begin{array}{l}10 \\
20 \\
30 \\
40 \\
50 \\
60\end{array}$ & $\begin{array}{l}1645.3 \\
409.37 \\
180.74 \\
100.68 \\
63.568 \\
43.388\end{array}$ & $\begin{array}{l}1641.2 \\
408.46 \\
180.19 \\
100.32 \\
63.366 \\
43.311\end{array}$ & $\begin{array}{c}- \\
408.96 \\
- \\
100.56 \\
- \\
43.351\end{array}$ & $\begin{array}{c}1646.9 \\
409.87 \\
180.63 \\
100.63 \\
63.547 \\
43.422\end{array}$ \\
\hline 0.3 & $\begin{array}{l}10 \\
20 \\
30 \\
40 \\
50 \\
60\end{array}$ & $\begin{array}{l}1640.1 \\
408.71 \\
180.44 \\
100.51 \\
63.463 \\
43.306\end{array}$ & $\begin{array}{l}1637.3 \\
407.54 \\
179.81 \\
100.13 \\
63.261 \\
43.252\end{array}$ & $\begin{array}{c}- \\
407.89 \\
- \\
100.29 \\
- \\
43.351\end{array}$ & $\begin{array}{c}1642.69 \\
408.81 \\
180.33 \\
100.38 \\
63.397 \\
43.3261\end{array}$ \\
\hline 0.4 & $\begin{array}{l}10 \\
20 \\
30 \\
40 \\
50 \\
60\end{array}$ & $\begin{array}{l}1624.0 \\
403.37 \\
178.04 \\
99.161 \\
62.807 \\
42.841\end{array}$ & $\begin{array}{l}1624.6 \\
404.41 \\
178.46 \\
99.391 \\
62.811 \\
42.958\end{array}$ & $\begin{array}{c}- \\
404.52 \\
- \\
99.469 \\
- \\
42.950\end{array}$ & $\begin{array}{c}1629.57 \\
405.54 \\
178.90 \\
99.586 \\
62.896 \\
42.985\end{array}$ \\
\hline
\end{tabular}


[Table 6] Fundamental frequency parameters, $\lambda=\sqrt{\omega^{2}\left(m r^{4} / E I_{0}\right)}$, for in-plane vibration of non-uniform curved beams with clamped-simply supported ends; $f(X)=[1+(2 \eta(X-0.5))]^{3}$

\begin{tabular}{|c|c|c|c|c|c|}
\hline$\eta$ & $\theta_{0}$ & Rayleigh-Ritz & C. D. M. & F. E. M. & DQM \\
\hline \multirow{6}{*}{0.1} & 10 & 1602.7 & 1604.3 & - & 1610.57 \\
\hline & 20 & 398.70 & 399.18 & 400.17 & 400.74 \\
\hline & 30 & 175.96 & 176.02 & - & 176.71 \\
\hline & 40 & 99.951 & 97.936 & 98.402 & 98.324 \\
\hline & 50 & 61.809 & 61.811 & - & 62.055 \\
\hline & 60 & 42.138 & 42.207 & 42.439 & 42.376 \\
\hline \multirow{6}{*}{0.2} & 10 & 1578.4 & 1576.2 & - & 1583.05 \\
\hline & 20 & 392.54 & 392.15 & 393.44 & 393.871 \\
\hline & 30 & 173.22 & 172.90 & - & 173.652 \\
\hline & 40 & 96.227 & 96.174 & 96.740 & 96.600 \\
\hline & 50 & 60.679 & 60.681 & - & 60.949 \\
\hline & 60 & 41.500 & 41.421 & 41.701 & 41.606 \\
\hline \multirow{6}{*}{0.3} & 10 & 1545.2 & 1539.7 & - & 1547.8 \\
\hline & 20 & 384.17 & 383.04 & 384.66 & 385.07 \\
\hline & 30 & 169.50 & 168.85 & - & 169.74 \\
\hline & 40 & 94.278 & 93.898 & 94.606 & 94.398 \\
\hline & 50 & 59.419 & 59.226 & - & 59.542 \\
\hline & 60 & 40.616 & 40.412 & 40.752 & 40.628 \\
\hline \multirow{6}{*}{0.4} & 10 & 1499.9 & 1494.1 & - & 1504.3 \\
\hline & 20 & 372.84 & 371.63 & 373.91 & 374.17 \\
\hline & 30 & 164.40 & 163.79 & - & 164.91 \\
\hline & 40 & 91.385 & 91.059 & 91.939 & 91.677 \\
\hline & 50 & 57.528 & 57.416 & - & 57.802 \\
\hline & 60 & 39.284 & 39.159 & 39.585 & 39.412 \\
\hline
\end{tabular}

studies relative to the number of grid point $N$ and the parameter $\delta$, respectively. Table 1 shows that the accuracy of the numerical solution increases with increasing $N$ and passes through a maximum. The optimal value for $N$ is found to be 11 to 13 using $\delta=1 \times 10^{-6}$ comparing with Rayleigh-Ritz's solutions. Table 2 shows the sensitivity of the numerical solution to the choice of $\delta$ using 13 grid points. From Table 2, the solution accuracy decreases due to numerical instabilities if $\delta$ becomes too big comparing with Rayleigh-Ritz's solutions. The optimal value for $\delta$ is found to be $1 \times 10^{-5}$ to $1 \times 10^{-6}$, which is obtained from trial-and-error calculations. Therefore, all results are calculated using 13 grid points and $\delta=1 \times 10^{-6}$ along the dimensionless axis.

The values of $\eta\left(=\frac{h_{1}}{h_{0}}-1\right)$ are taken to be from 0.1 to 0.4 for the comparisons. The results are summarized in Tables $3 \sim 6$. As it can be seen from Tables $3 \sim 6$, the numerical results by the DQM show excellent agreement with the solutions by the Rayleigh-Ritz and the C.D.M. for the case of simply-simply supported, clamped-clamped, simply supported-clamped, and clamped-simply supported ends. Tables $3 \sim 6$ also show that the numerical results by the DQM are good agreement with those by the SAP90 FEM. However, the SAP90 FEM was quite expensive because 90 finite elements were employed, as described by Auciello and De Rosa [4]. From Tables $3 \sim 6$, the frequency parameters by the DQM are generally higher than both those by the cells discretization method(C.D.M.) and the Ritz method. In general, as the values of $\eta\left(=\frac{h_{1}}{h_{0}}-1\right)$ ratios of beam cross sections become larger, the frequencies become more significant for the vibration.

\section{Conclusions}

The free in-plane vibration of asymmetric circular 
curved beams with varying cross-section is analyzed by the differential quadrature method (DQM) neglecting transverse shearing deformation. The frequency parameters are calculated for the beams with various opening angles and end conditions. The results are compared with existing numerical solutions by other methods (Rayleigh-Ritz, C.D.M., or FEM) for cases in which they are available. 1) It is found that the DQM gives the good accuracy. 2) It has also been shown that compare to the finite element method(90 elements used), the DQM requires less grid points(13 points used) are used to obtain the frequencies of the beams.

3) It requires the small computation times for the evaluation of the vibration characteristics reported in totality by Kukreti et al. [11].

\section{References}

[1] R. Hoppe, "The Bending Vibration of a Circular Ring", Crelle's J. Math., Vol. 73, pp. 158-170, 1871.

[2] A. E. H. Love, "A Treatise of the Mathematical Theory of Elasticity", 4th ed, Dover, New York, 1944.

[3] R. R. Archer, "Small Vibration of Thin Incomplete Circular Rings", Int. J. Mech. Sci., Vol. 1, pp. 45-56, 1960

[4] N. M. Auciello and M. A. De Rosa, "Free Vibrations of Circular Arches: A Review", J. Sound Vibr., Vol. 176, No. 4, pp. 433-458, 1994.

[5] R. E. Bellman and J. Casti, "Differential Quadrature and Long-Term Integration", J. Math. Anal. Applic., Vol. 34, No. 2, pp. 235-238, 1971.

[6] J. Park, "A Numerical Study on flexural Strength with the Spreading of Upper Reinforcement of Girder into the Adjoining Slab, J. KAIS, Vol. 8, No. 5, pp. 1179-1185. 2007.

[7] S. K. Jang, et al., "Application of Differential Quadrature to Static Analysis of Structural Components", Int. J. Numer. Mech. Engng, Vol. 28, No. 3, pp. 561-577, 1989.

[8] K. Kang and J. Han, "Analysis of a Curved beam Using Classical and Shear Deformable Beam Theories", Int. J. KSME., Vol. 12, No. 2, pp. 244-256, 1998.

[9] K. Kang and B. Kim, "In-Plane Vibration Analysis of Curved Beams Considering Shear Deformation Using
DQM", J. KAIS, Vol. 7, No. 5, pp. 793-800. 2006. [10] R. W. Hamming, "Numerical Methods for Scientists and Engineers", 2nd ed, McGraw-Hill, New York, 1973.

[11] A. R. Kukreti, et al., "Differential Quadrature and Rayleigh-Ritz Methods to Determine the Fundamental Frequency of Simply Supported Rectangular Plate with Linearly Varying Thickness ", J. Sound Vibr., Vol. 189, No. 1, pp. 103-122. 1996.

\section{Ki-Jun Kang}

[Regular Member]

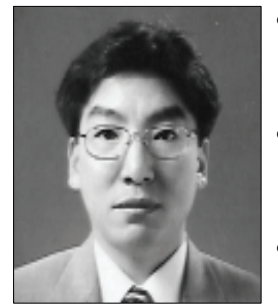

- Feb. 1984: Chungnam National University, Dept. of Mechanical Engineering (B.S),

- Dec. 1989: San Jose State University, Dept. of Mechanical Engineering (M.S)

- Dec. 1995: University of Oklahoma, Dept. of Mechanical Engineering (Ph.D)

- Mar. $1997 \sim$ current : Dept. of Automotive Engineering, Hoseo University, Professor

$<$ Research Interests $>$

Structural Analysis, Numerical Analysis, Vibration

\section{Young-Woo Kim}

[Regular Member]

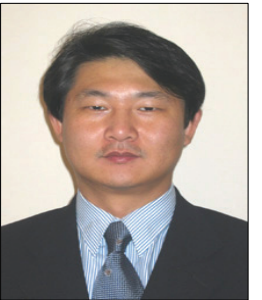

- Mar. 2005 : Duke Univ. School of Eng., Dept. of Civil and Environmental Engineering (M.S)

- Jan. 2006 : Duke Univ. School of Eng. Dept. of Civil and Environmental Eng. (Ph.D.)

- Jan. 2006 Jan. 2008 : Duke Univ. Civil and Environmental Eng., Adjunct Professor

- Mar. $2008 \sim$ current : Dept. of Automotive Engineering, Hoseo University, Assistant Professor

$<$ Research Interests $>$

Fluids Dynamics, Numerical Analysis 